\title{
PERENCANAAN PENETAPAN LABA MELALUI PENDEKATAN ANALISIS BREAK EVEN POINT (BEP) PERUSAHAAN WINGKO UD. TUJUH TUJUH ELOK BABAT LAMONGAN
}

\author{
Mohamad Rizal Nur Irawan \\ Fakultas Ekonomi, Universitas Islam Lamongan \\ rijal_peace@yahoo.co.id
}

\begin{abstract}
ABSTRAK
Penelitian ini merupakan jenis penelitian deskriptif kuantitatif pada perusahaan wingko UD.TUJUH TUJUH ELOK Babat dengan judul "perencanaan penetapan laba melalui pendekatan analisis Break even Point perusaan wingko UD.TUJUH TUJUH ELOK Babat Lamongan". Menganalisis perencanaan laba menggunakan metode break even point pada perusahaan wingkountuk mengetahui besar minimum serta besar target yang harus dicapai oleh perusahaan. Tahap tahap analisis yang harus dilalui oleh penulis adalah: (1) pemisahaan biaya (2) penghitungan analisis BEP (3) perhitungan perencanaan laba (4) perhitungan Margin Of Safety. Hasil penelitian dari perusahaan Wingko UD. TUJUH TUJUH ELOK Babat menunjukkan (1) dengan menggunakan analisis Break Even Point dapat membantu menetapkan perencanaan laba tahun 2014 pada perusahaan (2) perusahaan wingko UD. Tujuh Tujuh Elok dapat mencapai tingkat minimum penjualan dengan mencapai titik Break Even Point (3) besar margin of safety dapat dicapai oleh perusahaan dan tidak mengalami kerugian. Kesimpulan dari penelitian ini adalah dengan menggunakan analisis Break Even Point dapat membantu untuk menetapkan besar produksi dan jumlah volume penjualan agar tidak mengalami rugi.
\end{abstract}

Kata kunci: Break Even Point, Perencanaan Lab.

\section{PENDAHULUAN}

Tujuan mendirikan usaha tidak lain adalah untuk memperoleh keuntungan yang dapat dipergunakan untuk kelangsungan hidup. Kemajuan dan perkembanga usaha akan membawa akibat bagi pembangunan itu sendiri baik positif maupun negatif. Pada kalangan pengusaha itu sendiri, perkembangan dan kemajuan dunia usaha telah membawa kearah persaingan yang semakin ketat, sedangkan usaha untuk mencapai laba tidak dapat dipisahkan dari masalah penjualan, peningkatan penjualan yang tinggi bukan selalu berarti mendapatkan laba yang lebih besar.

Pada hakikatnya setiap usaha yang didirikan mempunyai harapan dikemudian hari, misalnya mengharapkan perkembangan yang sangat pesat. Perkembangan usaha pada dasarnya menginginkan tercapainya satu tujuan yaitu memperoleh laba dan 
menjaga kontinuitas usahanya. Adanya hal tersebut memaksa pengusaha untuk dapat bekerja keras agar dapat bersaing secara kompetitif.

Bagi pengusaha-pengusaha yang ingin survive dan sukses harus berusaha untuk meningkatkan volume penjualan yang dicapai perusahaan, karena hal ini akan mempengaruhi pencapaian laba usaha yang maksimal. Apabila perusahaan mampu meningkatkan volume penjualan, maka perusahaan mempunyai kemungkinan mampu meningkatkan jumlah keuntungan yang lebih besar, selain keuntungan yang meningkat dapat pula menaikkan efisiensi perusahaan.

Ukuran yang sering dipakai untuk menilai sukses tidaknya manajemen suatu perusahaan adalah laba yang diperoleh perusahaan. Sedangkan laba terutama dipengaruhi oleh tiga faktor yaitu harga jual produk, biaya, dan volume penjualan (Mulyadi, 2009 : 467). Biaya menentukan harga jual untuk mempengaruhi volume penjualan, sedangkan penjualan langsung mempengaruhi volume produksi dan volume produksi mempengaruhi biaya. Tiga faktor itu saling berkaitan satu sama lain. Oleh karena itu dalam perencanaan, hubungan antara biaya,

volume dan laba memegang peranan yang sangat penting.

Selain itu peran informasi juga sangat penting dalam dunia bisnis, terletak pada efektivitas tidaknya informasi yang digunakan oleh jajaran manajemen. Informasi dipandang dari sudut manajemen dapat berfungsi untuk membantu menggerakkan dan mengembangkan kegiatan perusahaan. Kelangsungan hidup dan pertumbuhan suatu perusahaan bergantung pada sistem informasi akuntansi.

Analisis impas atau analisis hubungan biaya, volume, dan laba merupakan teknik untuk menggabungkan, mengkoordinasikan dan menafsirkan data produksi dan distribusi untuk membantu manajemen dalam mengambil keputusan. Impas sendiri diartikan keadaan suatu usaha yang tidak memperoleh laba dan tidak menderita rugi. Dapat pula dengan kata lain suatu usaha dikatakan impas jika pendapatan sama dengan jumlah biaya. Dengan demikian analisis impas (break-even) adalah suatu alat yang digunakan untuk mempelajari hubungan antara biaya tetap, biaya variabel keuntungan, dan volume penjualan (Bambang Riyanto, 1997:359). 
Analisis Break Even Point (BEP) atau titik impas yang merupakan teknik analisa untuk mempelajari hubungan antara biaya total, laba yang diharapkan dan volume penjualan. Secara umum analisa ini juga memberikan informasi mengenai margin of safety yang mempunyai kegunaan sebagai indikasi dan gambaran kepada manajemen berapakah penurunan penjualan dapat ditaksir sehingga usaha yang dijalankan tidak menderita rugi. Selain itu apabila penjualan pada Break Event Point (BEP) dihubungkan dengan penjualan yang dianggarkan maka akan dapat diperoleh informasi tentang berapa jauh penjualan bisa turun sehingga industri tidak menderita rugi atau tingkat keamanan bagi industri dalam melakukan penurunan penjualan. Informasi tentang margin of safety ini dapat dinyatakan dalam prosentase atau rasio antara penjualan yang dianggarkan dengan volume penjualan pada tingkat impas.

Untuk dapat menentukan analisis Break Even Point (BEP) biaya yang terjadi harus dipisahkan menjadi biaya tetap dan biaya variabel. Biaya tetap adalah biaya yang jumlah totalnya tetap dan bertambah dengan adanya perubahan volume kegiatan. Biaya variabel adalah biaya yang jumlah totalnya berubah sebanding dengan perubahan volume kegiatan. Apabila suatu industri hanya mempunyai biaya variabel, maka tidak akan muncul masalah break even dalam industri tersebut. Masalah break even baru muncul apabila suatu industri disamping mempunyai biaya variabel juga mempunyai biaya tetap. Besarnya biaya variabel secara totalitas akan berubahubah sesuai dengan perubahan volume produksi, sedangkan besarnya biaya tetap secara totalitas tidak mengalami perubahan meskipun ada perubahan volume produksi.

Rencana manajemen mengenai kegiatan industri di masa yang akan datang pada umumnya dituangkan dalam anggaran, yang berisi taksiran pendapatan yang akan diperoleh dan biaya yang akan dikeluarkan untuk mendapatkan pendapatan tersebut. Bila mengadakan analisis secara langsung informasi yang tercantum dalam anggaran manajemen akan menemui kesulitan untuk memahami hubungan antara biaya, volume, laba. Analisis break even menyajikan informasi hubungan biaya, volume, dan laba kepada manajemen, sehingga memudahkannya dalam menganalisis faktor-faktor yang mempengaruhi 
pencapaian laba usaha di masa yang akan datang.

\section{TINJAUAN PUSTAKA}

\subsection{Manajemen Operasi}

Menurut G.R Terry (1997) dalam buku "manajemen operasi" (Dr. H. A. Rusdiana, M.M, 2014:132) perencanaan adalah tindakan memilih dan menghubungkan dan membuat serta menggunakan asumsi-asumsi mengenai masa yang akan datang dalam memvisualisasikan dan merumuskan aktivitas yang dianggap perlu untuk mencapai hasil yang diinginkan.

Menurut Bintaro Tjokroaminoto dalam husain usman (2008) adalah proses mempersiapkan kegiatan kegiatan secara sistematis yang akan dilakukan untuk mencapai tujuan tertentu. Prajudi atmosudirjo dalam husaini usman (2008) juga berpendapat bahwa perencanaan adalah perhitungan dan penentuan tentang suatu yang akan dijalankan dalam rangka mencapai tujuan tertentu, siapa yang melakukan, bagaimana, dan bagaimana cara melakukannya.

Perencanaan juga diartikan sebagai proses mendifinisikan tujuan organisasi, membuat strategi untuk mencapai tujuan itu, dan mengembangkan rencana aktivitas kerja organisasi. Perencanaan merupakan proses terpenting dari semua fungsi manajemen karena tanpa perencanaan fungsi-fungsi lain pengorganisasian, pengarahan dan pengontrolan tidak akan dapat berjalan.

Dari Beberapa pengertian Perencanaan Dapat Disimpulkan bahwa perencanaan adalah suatu proses untuk memutuskan mengenai tindakan apa yang diambil dan dilakukan atau memilih alternatif yang dianggap paling baik atau tepat, serta mendayaguna sumber daya yang dimiliki oleh perusahaan sesuai dengan alternatif yang dipilih untuk mencapai tujuan yang telah ditetapkan.

Menurut Mulyadi (2009 : 08) biaya adalah pengorbanan sumber ekonomi, yang diukur dengan satuan uang yang telah terjadi atau kemungkinan yang akan terjadi untuk tujuan tertentu.

Biaya adalah kas dan setara kas yang dikorbankan untuk memproduksi atau memperoleh manfaat atau keuntungan dimasa mendatang (Darsoni Prawironegoro \& Ari Purwanti, 2008 : 48)

Break even point adalah keadaan suatu usaha yang tidak smemperoleh laba dan tidak menderita rugi. Dengan kata lain, suatu usaha dikatakan impas jika jumlah pendapatan atau revenue 
(penghasilan) sama dengan jumlah biaya, atau apabila laba kontribusi hanya dapat digunakan untuk menutup biaya tetap saja. Dan analisis break even point adalah suatu cara untuk mengetahui volume penjualan minimum agar suatu usaha tidak menderita rugi, tetapi juga belum memperoleh laba dengan kata lain sama dengan nol) (Mulyadi 2009:230)

\subsection{Break Even Point}

Break even point adalah posisi dimana perusahaan tidak memperoleh laba dan tidak menderita kerugian. BEP atau titik impas sangan penting bagi manajemen untuk mengambil keputusan untuk menarik produk atau mengembangkan produk, atau untuk menutup anak perusahaan yang

Menurut Djarwanto dalam buku Dr. H. Rusdiana, M.M, (2014:192) Break even point adalah suatu keadaan impas, yaitu apabila telah disusun perhitungan laba dan rugi suatu periode tertentu, perusahaan tidak mendapat keuntungan dan tidak menderita rugi.

\subsection{Margin Of Safety}

Margin of safety menurut Abdul Halim dan Bambang S (2005:57)“ Margin Keamanan adalah selisih antara rencana penjualan (dalam unit atau satuan uang) dengan impas (dalam unit atau satua uang) penjualan". Margin of safety memberikan informasi tentang seberapa jauh realisasi penjualan dapat turun dari rencana penjualan agar perusahaan tidak menderita kerugian. Penurunan realisasi penjualan dari rencana penjualan maksimum harus sebesar magin of safety agar perusahaan tidak menderita kerugian.

Margin of safety menurut Bambang Riyanto (2010 :366) adalah : “mmargin of safety merupakan angka yang menunjukkan jarak penjualan yang direncanakan atau budget sales dengan penjualan break even. Dengan demikian maka margin of safety adalah juga menggambarkan jarak bats jarak, dimana jika penjualan melampaui batas tersebut maka penjualan akan mengalami kerugian."

Adapun tujuan dari penelitian ini adalah untuk mengetahui bagaimana perencanaan Laba menguunakan Analisis Break Even Point agar dapat apakah besar volume penjualan di Perusahaan wingko Tujuh Tujuh Elok Babat dapat mencapai tingkat Break Even Point serta Untuk mengetahui apakah besar margin of safety dapat diukur oleh Perusahaan wingko Tujuh 
Tujuh Elok Babat agar tidak mengalami kerugian.

\section{METODE PENELITIAN}

Jenis penelitian yang digunakan oleh penulis adalah pendekatan kuantitatif, . Penelitian ini berusaha menghasilkan data yang dapat dihitung berupa angkaangka yang dapat diperoleh dari data laporan Laba/Rugi yang diamati. Penelitian ini sebagai instrumen kunci, teknik pengumpulan data dilakukan secara gabungan, data yang dihasilkan bersifat kuantitatif, dan analisis data dilakukan secara induktif.

Dalam rangka menjawab permasalahan yang dirumuskan, maka digunakan analisis kuantitatif terhadap data yang terkumpul. Dalam penelitian ini penulisan ini menggunakan cara sebagai berikut :

Melakukan pemisahan biaya semi variabel dengan metode perkiraan

$$
B E P(R p)=\frac{F C}{1-\frac{V C}{5}}
$$

Dimana :

BEP $(\mathrm{Rp})=$ break Even Point atas dasar rupiah

FC = Biaya Tetap

$\mathrm{VC}=$ Biaya variabel

Teknik menentukan titik impas (BEP) dalam unit : langsung, jika metode perkiraan langsung digunakan, perkiraan biaya tetap dan biaya variabel suatu biaya semi variabel dibuat melalui pengalaman dan evaluasi sifat serta sebab timbulnya biaya.

Analisis Break Even Point

Teknik Persamaan :

$\mathrm{TC}=\mathrm{FC}+\mathrm{VC}$

$\mathrm{TR}=\mathrm{P} . \mathrm{Q}$

$\mathrm{BEP}=0=\mathrm{TR}-\mathrm{TC}$

Keterangan :

$\mathrm{TC}=$ Total Cost

$\mathrm{FC}=$ Fixed Cost

$\mathrm{VC}=$ Variable Cost

$\mathrm{P}$ = harga

$\mathrm{Q}=$ kuantitas

$\mathrm{BEP}=$ Break Even Point

Teknik menentukan titik impas (BEP) dalam rupiah :

Menurut Bambang Riyanto (2010:364) untuk melakukan analisis titik impas menggunakan rumus sebagai berikut :

$$
B E P(R p)=\frac{F C}{1-\frac{V C}{5}}
$$

Perhitungan laba yang direncanakan untuk mengambil keputusan tentang perencanaan laba maka rumus yang dapat digunakan adalah :

$$
\text { Penjualan }(R p)=\frac{F C}{1-\frac{V C}{5}}
$$

Atau

$$
\text { Penjualan }(\mathrm{Q})=\frac{\mathrm{FC}+\mathrm{Laba}}{p-V c}
$$


Dimana :

$\mathrm{FC}=$ Biaya Tetap

$\mathrm{P} \quad=$ Harga Jual Per Unit

$\mathrm{VC}=$ Biaya Variabel per Unit

$\mathrm{S} \quad=$ Volume penjualan

Menentukan Margin of Safety (tingkat keamanan) menurut Bambang Riyanto (2010:366) untuk menentukan Margin Of Safety dapat dihitung dengan menggunakan rumus sebagai berikut:Margin Pengamanan Penjualan=Total Penjualan-Penjualan Impas

Pengaman penjualan dapat juga dinyatakan dalam rupiah atau dalam bentuk prosentase. Prosentase ini dicari dengan membagi margin keamanan penjualan dengan jumlah rupiah penjualan, seperti dalam rumus berikut :

Margin Of safety =

$\frac{\text { p.yg direncanakan }- \text { p.BEP }}{\text { penjualan yang direncanakan }} X 100 \%$

\section{PEMBAHASAN}

\subsection{Analisis Break Even Point}

Tabel. 1 Margin contribusi UD. TUJUH

TUJUH ELOK Babat Lamongan

\begin{tabular}{|l|c|c|c|c|}
\hline Bln & TR & VC & CM & CMR \\
\hline 1 & 58.800 .000 & 21.975 .000 & $62,62 \%$ & 36.824 .000 \\
\hline 2 & 54.880 .000 & 20.110 .000 & $63,35 \%$ & 34.770 .000 \\
\hline 3 & 60.760 .000 & 21.657 .000 & $64,35 \%$ & 39.102 .500 \\
\hline 4 & 52.920 .000 & 19.927 .500 & $62,34 \%$ & 32.992 .500 \\
\hline 5 & 50.960 .000 & 19.245 .000 & $62,23 \%$ & 31.715 .000 \\
\hline 6 & 64.680 .000 & 21.022 .500 & $62,68 \%$ & 40.657 .500 \\
\hline 7 & 62.720 .000 & 22.340 .000 & $64,38 \%$ & 40.380 .000 \\
\hline
\end{tabular}

\begin{tabular}{|l|r|r|r|l|}
\hline Bln & \multicolumn{1}{c|}{ TR } & \multicolumn{1}{c|}{ VC } & CM & CMR \\
\hline 8 & 60.900 .000 & 21.683 .500 & $64,39 \%$ & 39.216 .500 \\
\hline 9 & 78.400 .000 & 29.310 .000 & $62,61 \%$ & 49.090 .000 \\
\hline 10 & 68.600 .000 & 25.771 .250 & $62,43 \%$ & 42.825 .750 \\
\hline 11 & 58.800 .000 & 21.975 .000 & $62,62 \%$ & 36.824 .000 \\
\hline 12 & 88.200 .000 & 32.128 .000 & $63,57 \%$ & 56.072 .000 \\
\hline Jml & 762.600 .000 & 280.144 .750 & $63,13 \%$ & $\mathbf{4 8 0 . 4 6 9 . 7 5 0}$ \\
\hline
\end{tabular}

Sumber data: UD. Tujuh Tujuh Elok, data diolah

Perhitungan margin contribusi

Contribution Margin = TR $-V C$

1. $\mathrm{CM}=58.800 .000-21.975 .000=36.824 .000$ CMR $\quad=36.824 .000=62,62 \%$

$$
\overline{58.800 .000}
$$

2. $\mathrm{CM}=54.880 .000-20.110 .000=34.770 .000$

CMR

$$
=34.770 .000=63,35 \%
$$

$$
\overline{54.880 .000}
$$

3. $\mathrm{CM}=60.760 .000-21.657 .000=$ 39.102 .500

$$
\text { CMR }=39.102 .500=64,35 \%
$$

$$
\overline{60.760 .000}
$$

4. $\mathrm{CM}=52.920 .000-19.927 .500=$ 32.992 .500

$\mathrm{CMR}=32.992 .500=0,6234=62,34 \%$

$$
\overline{52.920 .000}
$$

5. $\mathrm{CM}=50.690 .000-19.245 .000=$ 31.715 .000

CMR $=31.715 .000=0,6223=62,23 \%$

$$
50.690 .000
$$

6. $\mathrm{CM}=64.680 .000-21.022 .500=$ 40.657 .500

CMR $=40.657 .500=0,6268=62,68 \%$

$$
\mathrm{CM} \quad=62.720 .000-22.340 .000=
$$
40.380 .000

$$
\begin{aligned}
\text { CMR } & =\frac{36.824 .000}{62.720 .000}=0,6438=64,38 \% \\
& =60.900 .000-21.683 .500 \\
& =39.216 .500
\end{aligned}
$$




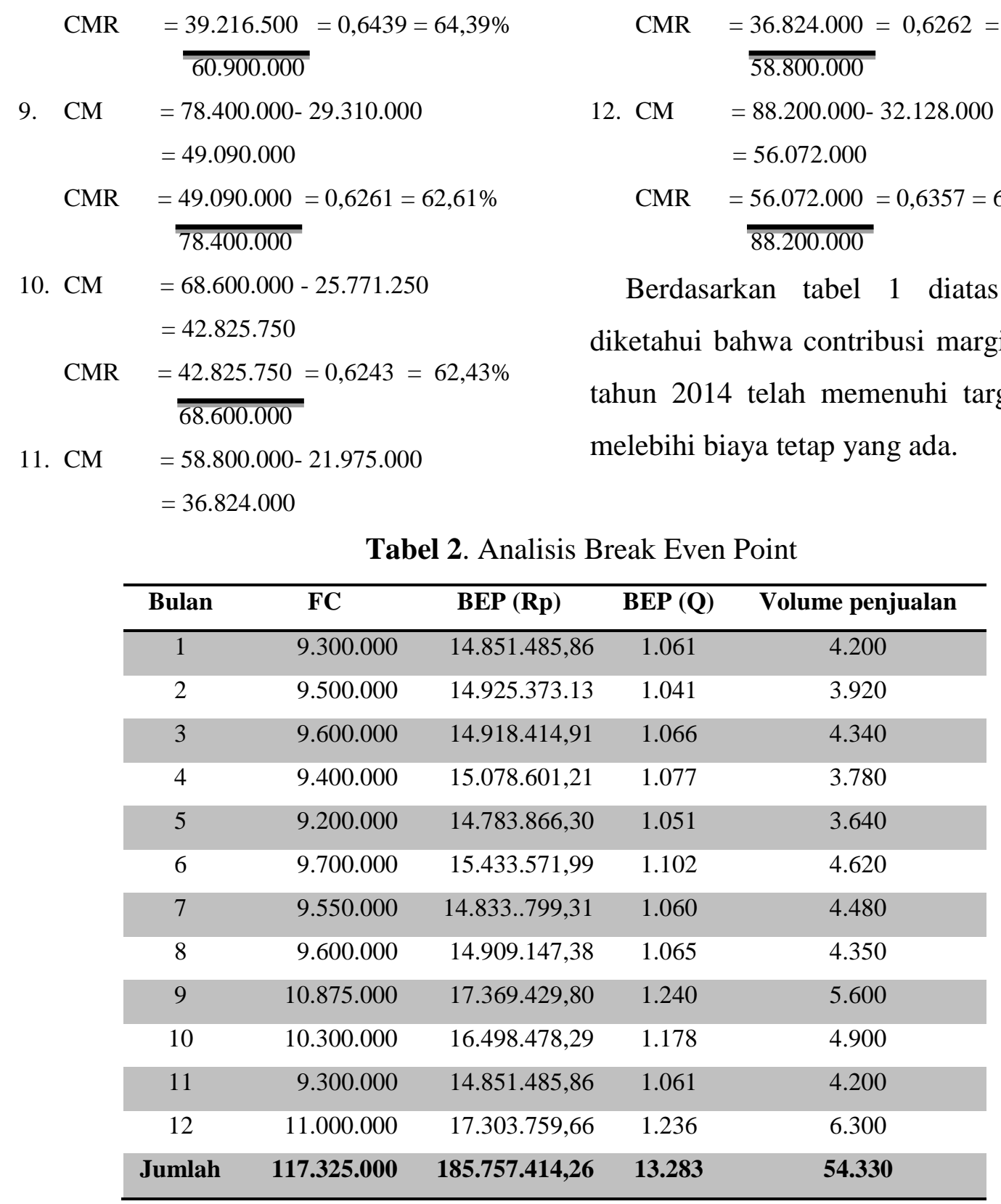

Sumber data: UD. Tujuh Tujuh Elok, data diolah

Perhitungan Break Even Point

$\begin{aligned} & \operatorname{BEP}(\mathrm{UNIT})= \frac{\text { Biaya Tetap }}{\mathrm{BEP}(\mathrm{Rp})}= \\ &= \text { Biaya Tetap } \\ & \text { Ratio CM }\end{aligned}$

$$
\begin{array}{ll}
\text { Januari } & \\
\operatorname{BEP}(\mathrm{Rp}) & =\frac{9.300 .000}{62,62 \%} \\
& =\frac{14.851 .485,14}{36.825 .000 / 4200} \\
\operatorname{BEP}(\text { Unit }) & =\frac{9.300 .000}{} \\
& =1.061 \mathrm{biji}
\end{array}
$$




\section{Pebruari}

$$
\begin{aligned}
\mathrm{BEP}(\mathrm{Rp}) \quad & =\frac{9.500 .000}{63,65 \%} \\
& =14.925 .373,13 \\
\mathrm{BEP} \text { (Unit) } \quad & \frac{9.500 .000}{34.770 .000 / 3920} \\
& =1.071 \mathrm{biji}
\end{aligned}
$$

Maret

$$
\begin{aligned}
\mathrm{BEP}(\mathrm{Rp}) & =\frac{9.600 .000}{64,35 \%} \\
& =14.918 .414,91 \\
\mathrm{BEP} \text { (Unit) } & =\frac{9.600 .000}{39.102 .500 / 4340} \\
& =1.066 \mathrm{biji}
\end{aligned}
$$

April

$$
\begin{aligned}
\mathrm{BEP}(\mathrm{Rp}) & =\frac{9.400 .000}{62,34 \%} \\
& =15.078 .601,21 \\
\mathrm{BEP}(\text { Unit }) & =\frac{9.400 .000}{32.992 .500 / 3780} \\
& =1.077 \mathrm{biji}
\end{aligned}
$$

Mei

$$
\begin{array}{ll}
\mathrm{BEP}(\mathrm{Rp}) & =\frac{9.200 .000}{62,23 \%} \\
& =\frac{14.783 .866,30}{31.715 .000 / 3640} \\
\mathrm{BEP} \text { (Unit) } & =\frac{9.200 .000}{} \\
& =\frac{1.051 \mathrm{biji}}{\mathrm{Juni}} \\
\mathrm{BEP} \text { (Rp) } & =\frac{9.700 .000}{62,85 \%} \\
& =15.433 .571,99 \\
\mathrm{BEP} \text { (Unit) } & =\frac{9.700 .000}{40.657 .500 / 4620} \\
& =1.102 \mathrm{biji}
\end{array}
$$

Juli

$$
\begin{aligned}
\mathrm{BEP}(\mathrm{Rp}) & =\frac{9.550 .000}{64,38 \%} \\
& =14.833 .779,31
\end{aligned}
$$

$$
\begin{aligned}
\mathrm{BEP}(\text { Unit }) & =\frac{9.550 .000}{40.380 .000 / 4480} \\
& =1.060 \mathrm{biji}
\end{aligned}
$$

\section{Agustus}

$$
\begin{aligned}
\operatorname{BEP}(\mathrm{Rp}) & =\frac{9.600 .000}{64,39 \%} \\
& =14.909 .147,38
\end{aligned}
$$

$$
\begin{aligned}
\mathrm{BEP}(\text { Unit }) & =\frac{9.600 .000}{39.216 .500 / 4350} \\
& =1.065 \mathrm{biji}
\end{aligned}
$$

September

$$
\begin{aligned}
\operatorname{BEP}(\mathrm{Rp}) & =\frac{10.875 .000}{62,61 \%} \\
& =17.369 .429,80 \\
\mathrm{BEP}(\text { Unit }) & =\frac{10.875 .000}{49.090 .000 / 5600} \\
& =1.240 \mathrm{biji}
\end{aligned}
$$

\section{Oktober}

$$
\begin{aligned}
\operatorname{BEP}(\mathrm{Rp}) & =\frac{10.300 .000}{62,43 \%} \\
& =16.498 .478,29 \\
\mathrm{BEP}(\text { Unit }) & =\frac{10.300 .000}{42.825 .750 / 4900}
\end{aligned}
$$$$
=1.178 \mathrm{biji}
$$

November

$$
\begin{aligned}
\operatorname{BEP}(\mathrm{Rp}) & =\frac{9.300 .000}{62,62 \%} \\
& =14.851 .485,14 \\
\mathrm{BEP}(\text { Unit }) & =\frac{9.300 .000}{36.825 .000 / 4200} \\
& =106,06 \mathrm{biji}
\end{aligned}
$$

\section{Desember}

$$
\begin{aligned}
\mathrm{BEP}(\mathrm{Rp}) & =\frac{11.000 .000}{63,57 \%} \\
& =17.303 .759,66 \\
\mathrm{BEP} \text { (Unit) } & =\frac{11.000 .000}{56.072 .000 / 6.300} \\
& =1.326 \mathrm{biji}
\end{aligned}
$$


Berdasarkan tabel 2 diatas dapat diketahui bahwa Break Even Point pada tahun 2014 telah memenuhi target dan melebihi target minimum penjualan yang ada.

Tabel 3. Laba dan Target Penjualan

\begin{tabular}{|c|c|c|c|}
\hline Bulan & \multirow{2}{*}{ Laba } & \multicolumn{2}{|c|}{ Target penjualan } \\
\cline { 3 - 4 } & & Rp & Q \\
\hline 1 & 27.515 .000 & 37.200 .000 & 4.166 \\
\hline 2 & 25.270 .000 & 30.776 .860 & 3.897 \\
\hline 3 & 29.502 .500 & 43.009 .400 & 4.340 \\
\hline 4 & 23.592 .500 & 24.102 .564 & 3.780 \\
\hline 5 & 22.515 .000 & 20.444 .444 & 3.639 \\
\hline 6 & 31.457 .000 & 41.157 .500 & 4.490 \\
\hline 7 & 30.870 .000 & 40.415 .535 & 4.559 \\
\hline 8 & 29.616 .500 & 39.212 .250 & 4.350 \\
\hline 9 & 38.215 .000 & 48.598 .704 & 5.544 \\
\hline 10 & 32.529 .000 & 42.826 .000 & 4.900 \\
\hline 11 & 27.515 .000 & 37.200 .000 & 4.166 \\
\hline 12 & 45.072 .000 & 57.591 .623 & 6.300 \\
\hline jumlah & $\mathbf{3 3 8 . 3 9 9 . 5 0 0}$ & $\mathbf{4 6 3 . 5 3 7 . 8 8 0}$ & $\mathbf{5 4 . 1 3 1}$ \\
\hline Sumber & 2ata: UD & 1401 & \\
\hline
\end{tabular}

Sumber data: UD. Tujuh Tujuh Elok, data diolah

Perhitungan yang digunakan untuk menentukan perencanaan target penjualan adalah sebagai berikut :

$$
\begin{aligned}
& \text { Penjualan }(\mathrm{Rp})=\frac{\mathrm{FC}}{1-\frac{\mathrm{VC}}{\mathrm{S}}} \\
& \text { Penjualan }(\mathrm{Q})=\mathrm{FC}+\text { Laba }
\end{aligned}
$$$$
\text { Januari }
$$$$
\begin{aligned}
\text { Penjualan }(\mathrm{Rp}) & =\frac{9.300 .000}{\frac{1-5250}{4200}} \\
& =37.200 .000
\end{aligned}
$$

$$
\begin{aligned}
\text { Penjualan }(\mathrm{Q}) \quad & =\frac{9.300 .000+27.151 .000}{14.000-5.250} \\
& =4165 \mathrm{Biji}
\end{aligned}
$$

\section{Pebruari}

Penjualan $(\mathrm{Rp})=\underline{9.500 .000}$

$$
1-\underline{5130}
$$$$
3920
$$

$$
\begin{aligned}
& =30.776 .859,5 \\
\text { Penjualan }(\mathrm{Q}) \quad & =\frac{9.500 .000+25.070 .000}{14.000-5.130} \\
& =3897 \mathrm{Biji}
\end{aligned}
$$

\section{Maret}

Penjualan $(\mathrm{Rp}) \quad=9.600 .000$

$$
\begin{aligned}
& \frac{1-4990}{4340} \\
& =43.009 .400 \\
\text { Penjualan }(\mathrm{Q}) \quad & =\frac{9.600 .000+29.502 .000}{14.000-4990} \\
& =4340 \mathrm{Biji}
\end{aligned}
$$

\section{April}

$$
\begin{aligned}
\text { Penjualan }(\mathrm{Rp}) & =\frac{9.400 .000}{\frac{1-5227}{3780}} \\
& =24.102 .564 \\
\text { Penjualan }(\mathrm{Q}) & =\frac{9.400 .000+23.592 .500}{14.000-5272} \\
& =3780 \mathrm{Biji}
\end{aligned}
$$

\section{Mei}

$$
\begin{aligned}
\text { Penjualan (Rp) } & =\frac{9.200 .000}{1-\underline{5287}} \\
& =20.444 .444,4 \\
\text { Penjualan }(Q) & =\frac{9.200 .000+22.515 .000}{14.000-5.287} \\
& =3639 \mathrm{Biji}
\end{aligned}
$$




\section{Juni}

Penjualan $(\mathrm{Rp}) \quad=9.700 .000$

$$
\text { 1- } \underline{4835}
$$$$
=41.157 .500
$$

Penjualan $(\mathrm{Q}) \quad=\underline{9.700 .000+31.457 .500}$

$$
14.000-4835
$$

$$
=4490 \mathrm{Biji}
$$

\section{Juli}

$$
\begin{aligned}
\text { Penjualan }(\mathrm{Rp}) & =\frac{9.550 .000}{\frac{1-\underline{5135}}{4480}} \\
& =40.415 .535 \\
\text { Penjualan }(\mathrm{Q}) & =\frac{9.550 .000+30.870 .000}{14.000-5.135} \\
& =4599 \mathrm{Biji}
\end{aligned}
$$

\section{Agustus}

$$
\begin{aligned}
& \text { Penjualan }(\mathrm{Rp})=\frac{9.600 .000}{\frac{1-\underline{4985}}{4350}} \\
&=39.215 .250 \\
& \text { Penjualan }(\mathrm{Q}) \quad=\frac{9.600 .000+29.616 .500}{14.000-4985} \\
&=4.350 \mathrm{Biji}
\end{aligned}
$$

\section{September}

$$
\begin{aligned}
\text { Penjualan }(\mathrm{Rp}) & =\frac{10.385 .000}{\frac{1-\underline{5234}}{5600}} \\
& =48.598 .704 \\
\text { Penjualan }(\mathrm{Q}) & =\frac{10.385 .000+38.215 .000}{14.000-5.234} \\
& =5544 \mathrm{Biji}
\end{aligned}
$$

\section{Oktober}

$$
\begin{aligned}
\text { Penjualan }(\mathrm{Rp}) & =\frac{10.300 .000}{\frac{1-\underline{5260}}{4900}} \\
& =42.826 .000 \\
\text { Penjualan (Q) } & =\frac{10.300 .000+32.529 .000}{14.000-5.260}
\end{aligned}
$$

$$
=4900 \mathrm{Biji}
$$

\section{November}

$$
\begin{aligned}
\text { Penjualan }(\mathrm{Rp}) & =\frac{9.300 .000}{\frac{1-\underline{5250}}{4200}} \\
& =37.200 .000 \\
\text { Penjualan }(\mathrm{Q}) \quad & =\frac{9.300 .000+27.151 .000}{14.000-5.250} \\
& =4165 \mathrm{Biji}
\end{aligned}
$$

\section{Desember}

$$
\begin{aligned}
\text { Penjualan }(\mathrm{Rp}) & =\frac{11.000 .000}{1-\underline{5100}} \\
& =57.591 .623 \\
\text { Penjualan }(\mathrm{Q}) & =\frac{11.000 .000+45.072 .000}{14.000-5.100} \\
& =6300 \mathrm{Biji}
\end{aligned}
$$

Perhitungan Margin Of safety

Margin keamanan $=$ total penjualan penjualan titik impas

Margin of safety (\%)

$=$ p.yang dianggarkan $-\mathrm{p}$. titik impas

$$
\text { Total penjualan }
$$

\section{Januari}

$$
\begin{aligned}
\mathrm{M} / \mathrm{S}(\mathrm{Rp}) & =58.800 .000-14.81 .485,14 \\
& =43.948 .514,86 \\
\mathrm{M} / \mathrm{S}(\%) & =\frac{43.948 .514,86}{58.800 .000} \\
= & 0,7474 \\
= & 74,74 \%
\end{aligned}
$$

\section{Pebruari}

$$
\begin{aligned}
\mathrm{M} / \mathrm{S}(\mathrm{Rp}) & =54.880 .000-14.925 .373,13 \\
& =39.954 .626,87 \\
\mathrm{M} / \mathrm{S}(\%) & =39.954 .626,87 \\
& =0,7280=72,80 \%
\end{aligned}
$$




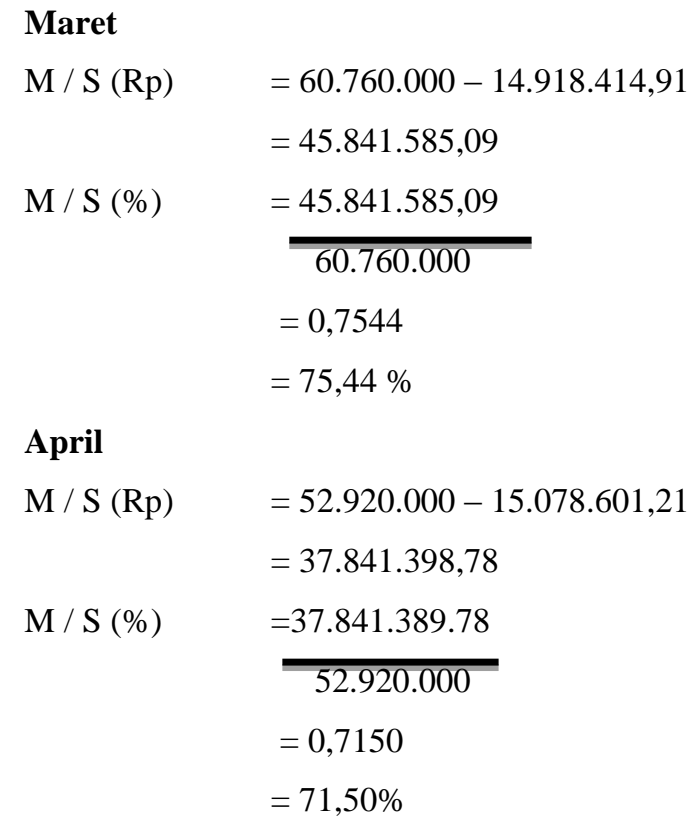

Mei

$\mathrm{M} / \mathrm{S}(\mathrm{Rp}) \quad=50.960 .000-14.783 .866 .30$

$=36.176 .133,7$

$\mathrm{M} / \mathrm{S}(\%) \quad=\quad 36.176 .133,7$ 50.960 .000

$=0,7098$

$=70,98 \%$

Juni

$\mathrm{M} / \mathrm{S}(\mathrm{Rp}) \quad=64.680 .000-15.433 .571,99$

$=49.246 .428,01$

$\mathrm{M} / \mathrm{S}(\%) \quad=49.246 .428,01$

64.680 .000

$=0,7613$

$=76,13 \%$

Juli

$\mathrm{M} / \mathrm{S}(\mathrm{Rp}) \quad=62.720 .000-14.833 .799,31$

$=47.886 .200,69$

$\mathrm{M} / \mathrm{S}(\%) \quad=47.886 .200,69$

62.720 .000

$=0,7634$

$=76,34 \%$

Agustus

$\mathrm{M} / \mathrm{S}(\mathrm{Rp}) \quad=60.900 .000-14.909 .147,38$

$=45.990 .852,62$

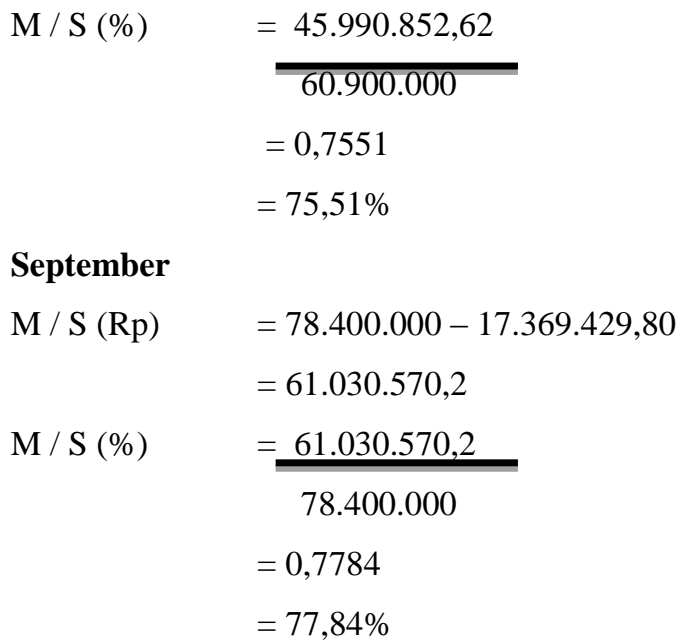

Oktober

$\mathrm{M} / \mathrm{S}(\mathrm{Rp}) \quad=68.600 .000-16.498 .478,29$

$=52 \cdot 101 \cdot 521,71$

$\mathrm{M} / \mathrm{S}(\%) \quad=52.101 .521,71$

68.600 .000

$=0,7594$

$=75,94 \%$

November

$\mathrm{M} / \mathrm{S}(\mathrm{Rp}) \quad=58.800 .000-14.81 .485,14$

$=43.948 .514,86$
$\mathrm{M} / \mathrm{S}(\%) \quad=43.948 .514 .86$
58.800 .000
$=0,7474$
$=74,74 \%$

Desember

$\mathrm{M} / \mathrm{S}(\mathrm{Rp}) \quad=88.200 .000-17.303 .759,66$

$=70.2896 .240,34$

$\mathrm{M} / \mathrm{S}(\%) \quad=70.2896 .240,34$

88.200 .000

$=0,8038$

$=80,38 \%$

Realisasi penjualan serta laba yang diperoleh pada tahun 2014 talah mencapai target dan laba yang direncanakan pada tahun 2014. Minimum penjualan pada tahun tersebut 
telah dicapai dan snaggup melebiki target yang telah direncanakan dan mencapai tingkat break even point oleh perusahaan. Sehingga perusahaan dapat merencanakan dan mencapai target yang direncanakan.

Pada tahun 2014 laba yang diperoleh oleh perusahaan sebesar Rp.338.399.500, ini sudah melebihi dan mampu menutupi biaya tetap selama 2014 sebesar Rp.117.325.000, Bahwa Nilai minimum penjualan perusahaan sebesar Rp.480.469.750 telah dicapai oleh perusahaan dalam mencapai titik Break Even Point sebesar Rp. 185.757.414,26

Pada kondisi tahun 2014, UD TUJUH TUJUH ELOK telah mengalami tingkat keamanan yang signifikan,karena memiliki tingkat prosentasi lebih dari nol dan hampir mendekati $100 \%$ dan itu menandakna bahwa perusahaan dalam keadaan aman dan tidak rugi.

Dengan metode ini sangat efektif untuk merencanakan dan mengukur apakah perusahaan mengalami rugi atau untung, serta dapat mehitung target laba yang ingin diperoleh agar perusahaan mencapai laba.

\section{PENUTUP}

\subsection{Simpulan}

Berdasarkan pembahasan diatas dikatakan bahwa suatu perusahaan mengalami laba atau tidak itu tergantuk berapa besar mereka mampu mencapai target yang diinginkan. Apabila output yang dilakukan lebih besar dari target maka perusahaan tersebut dapat dikatakan untuk, dan begitu juga sebaliknya.

Break even point adalah alat analisis yang sangat efektif untuk membantu merencanakan laba atau target penjualan yang ingin dicapai perusahaan untuk mendapatkan untuk. Pada tahun 2014 perusahaan telah membuktikan bahwa dengan menggunakan metode tersebut dapat mempermudah perusahaan untuk melakukan perencanaan laba.

\subsection{Saran}

Untuk kedepannya diharapkan perusahaan mau menggunakan metode analisis break even point dan margin of safety untuk merencanakan laba da target penjualan, agar perusahaan kedepannya dapat mendapatkan keuntungan yang lebih dan menjadikan perusahaan terus mengalami peningkatan dalam volume penjualan dan laba. 


\section{DAFTAR PUSTAKA}

Darsono, 2009, Manajemen Keuangan :

Kajian Pengambilan Keputusan

Bisnis Berbasis Analisis Keuangan,

Nusantara Consulting, Jakarta.

Horngern, Charles T., Datar, Srikant M.,

Foster, George., 2006, Akuntansi

Biaya. Edisi Dua Belas, Erlangga, Jakarta.

Mulyadi, 2010, Akuntansi Biaya Edisi 6.

UPP-AMP YKPN, Yogyakarta.

Riyanto Bambang, 2010, Dasar - dasar

pembelajaran perusahaan Edisi 4, BPFE, Yogyakarta.

Rusdiana, 2014, Manajemen Operasi,

CV.Pustaka Setia, Bandung. 